\title{
Criminologie
}

\section{Éditorial : adolescence et désespoir du sens}

\section{Jean Lajoie}

Volume 23, numéro 1, 1990

Nouvelles violences à l'adolescence

URI : https://id.erudit.org/iderudit/017285ar

DOI : https://doi.org/10.7202/017285ar

Aller au sommaire du numéro

Éditeur(s)

Les Presses de l'Université de Montréal

ISSN

0316-0041 (imprimé)

1492-1367 (numérique)

Découvrir la revue

Citer ce document

Lajoie, J. (1990). Éditorial : adolescence et désespoir du sens. Criminologie, 23(1), 3-5. https://doi.org/10.7202/017285ar d'utilisation que vous pouvez consulter en ligne.

https://apropos.erudit.org/fr/usagers/politique-dutilisation/ 
Les interdits dont la société affuble l'adolescence, sous le couvert de la légitimité de l'intention pédagogique, ne sont-ils pas, fondamentalement, les garants de la sécurité de notre espace vital? Les adolescents font peur parce qu'ils ne sont plus ceux que nous avons été et peut-être parce que nous ne reconnaissons pas ce qu'ils sont devenus.

La jeunesse, on l'a dit souvent, c'est l'espoir d'un monde meilleur; c'est en fait notre seul espoir! L'exaspération que nous nourrissons souvent face à ses incartades traduit, sans doute, notre propre exaspération face à nos espoirs déçus mais aussi face au vide existentiel et valoriel d'une société dont nous voulions pourtant libérer la «conscience malheureuse» et que nous voulions lui léguer en guise d'héritage.

À l'époque de la société prétechnologique, l'homme s'était résigné à fuir les contraintes inhérentes à l'existence dans le rêve, à travers le mécanisme psychanalytique de la sublimation: la religion, l'art, la patrie, l'honneur, la famille. L'homme arrivait à fuir sa conscience malheureuse à travers une idéalisation, une sublimation de la réalité qui n'était, au fond, qu'un rêve, mais un rêve conscient. L'existence comportait un aspect pénible inéluctable et l'entreprise onirique aidait l'homme à le supporter.

La société postindustrielle, en plus de prétendre le libérer des contraintes du travail, croyait lui apporter une libération totale (la morale contraignante, l'aliénation religieuse, sociale, économique). Puisque l'aspect pénible de l'existence s'estompait, dans cette logique, l'univers sublimé ou le rêve n'avait plus sa raison d'être. Marcuse parle de la «désublimation de la conscience malheureuse.»

Mais cette libération, le diagnostic se confirme de jour en jour, semble s'avérer un leurre. En fait, la société, en même temps qu'elle favorise cette libération, la circonscrit et l'oriente.

On assiste, en même temps, à une intensification sans précédent de la promotion de l'exploitation sexuelle, de l'usage de psychotropes, de la course

* Conseiller aux programmes à la Direction de la protection de la jeunesse du Centre de services sociaux du Montréal Métropolitain, 1001, boul. de Maisonneuve est, Montréal, Québec, H2L 4R5. 
effrénée à l'acquisition des biens de consommation, de la violence sous toutes ses formes et du rendement comme moteur économique.

En même temps, on assiste à une répression judiciaire et pénale grandissante de certains comportements et les gouvernements, incapables de se doter de politiques familiales cohérentes, sont devenus les artisans de la défavorisation sociale des masses laborieuses.

La conscience malheureuse, privée du rêve, en proie à l'insécurité morale, à la misère affective et incapable de répondre aux appels de la société de consommation, n'a plus d'exutoire que dans la violence, et pire, dans l'agression.

À l'instar du monde adulte, les adolescents n'échappent pas à cette dialectique diabolique. L'adolescence, construit social, née dans nos sociétés occidentales avec l'avènement de l'industrialisation, n'en finit plus de s'éterniser faute de la permission d'accéder aux responsabilités de l'âge adulte. Et comme le dit si bien Jean Roy: «Finalement, dans ce désespoir du sens, la masse flottante des jeunes, sans cesse ballottée par les mouvements éphémères de la mode, crie son manque innomé par la violence.»

C'est un peu à partir de cette réflexion que la revue Criminologie vient proposer à ses lecteurs un certain regard sur diverses formes de «violence à l'adolescence». L'objectif de ce numéro thématique est à la fois de dédramatiser et de resituer dans l'ordre des choses «les violences» chez les jeunes et de provoquer un questionnement sur les attitudes du monde adulte face à ce que la couverture médiatique tend à faire, une pandémie.

Camille Messier, d'abord, nous fait part des résultats de son enquête auprès d'une population de jeunes aux prises avec des «troubles de comportement» et du traitement en centre de réadaptation dont ils ont été l'objet, à la suite d'une ordonnance de cour. Elle nous décrit leur violence agie mais aussi leur violence subie et questionne les enjeux de l'intervention.

Marc Le Blanc, pour sa part, nous décrit la trajectoire sociale de la violence chez les jeunes Québécois au cours des dernières décennies à travers, notamment, le phénomène des bandes d'adolescents. Il aborde également le phénomène à l'intérieur du cheminement personnel de ces jeunes et propose des pistes pour sa prévention.

Roger Rondeau s'attaque à un type très particulier de violence, celui de la conduite homicidaire. Il nous fait part de ses réflexions à partir de la présentation de deux histoires de cas et tente de resituer ces conduites à l'intérieur de la dynamique de personnalité de ces adolescents.

Enfin, Suzette Laforest et Richard Paradis nous décrivent les résultats de leur intervention auprès de jeunes trouvés coupables de conduites sexuelles 
abusives. Il s'agit d'un projet expérimental : une intervention de groupe centrée sur le développement psychosexuel de ces adolescents, en complémentarité avec l'intervention individuelle.

Pour les articles hors thème, conformément à la politique de la revue, nous proposons d'abord un tableau de la pratique de la détention provisoire au Québec, brossé par Marie-Luce Garceau. On apprend qu'au cours de la dernière décennie on a de plus en plus recours à cette mesure; il s'agit d'une réflexion non seulement sur le caractère abusif de son utilisation mais aussi d'un questionnement sur la philosophie même de sa pratique.

\section{RÉFÉRENCES}

BLOCH, H. et NIEDERHOFFER, A. (1969), Les Bandes d'adolescents, Petite bibliothèque Payot, Paris.

LAJOIE, J. (1977), «L'Avenir utopique de la criminalité», Crime andlet Justice, vol. 5, $N^{\circ} 1$, Les Éditions de l'Université d'Ottawa.

MARCUSE, H. (1968), L'Homme unidimensionnel, Éditions de Minuit, Paris.

MARCUSE, H. (1963), Éros et civilisation, Éditions de Minuit, Paris.

ROY, J. (1989), «L'Inévitable violence», Apprentissage et Socialisation, vol. 12, N 1, Conseil québécois pour l'enfance et la jeunesse. 